\title{
Identifikasi Perilaku Perjalanan Melalui Metode Critical Path Method (CPM)
}

\author{
Urban Travel Behavior Identification Using Critical Path Method
}

\author{
Lulu Mari Fitria ${ }^{1}$, Mutiasari Kurnia Devi ${ }^{1}$, Muhammad Sani Roychansyah ${ }^{2}$, Yori Herwangi ${ }^{2}$, \\ dan Siti Nurjanah ${ }^{1}$
}

Diterima: 1 November 2019 Disetujui: 2 April 2020

\begin{abstract}
Mobilisasi penduduk di kawasan perkotaan tiap tahun mengalami peningkatan seiring dengan pertambahan jumlah penduduk dan perkembangan kawasan perkotaan. Perilaku perjalanan penduduk dikawasan perkotaan dapat diklasifikasikan berdasarkan kararteristik perjalanannya. Identifikasi perilaku perjalanan masyarakat Kawasan Perkotaan Yogyakarta didasarkan pada asal-tujuan perjalanan dan lama waktu perjalanan masingmasing tingkatan usia. Hal tersebut akan memiliki pengaruh terhadap pola perjalanan di lingkungan perkotaan melalui pemetaan secara spasial. Metode yag digunakan dalam penelitian ini adalah menggunakan metode critical path. Critical Path Methode (CPM) digunakan untuk mengetahui jalur optimum yang ditempuh masyarakat berdasarkan durasinya, yang pada penelitian ini CPM digunakan untuk mengetahui rata-rata perjalanan masyarakat berdasarkan kelompok usia jika ditinjau dari jarak, lama perjalanan dan banyaknya perjalanan harian. Berdasarkan hasil analisis diketahui bahwa rata-rata usia 1522 tahun dan 31-37 tahun melakukan waktu perjalanan paling tinggi yakni sekitar 9 jam dan usia 23-30 tahun rata-rata menempuh perjalanan paling panjang yakni 12,5 km. Sebaran mobilisasi perilaku perjalanan di KPY rata-rata menuju pusat Kawasan Perkotaan Yogyakarta. Berdasarkan sebaran lokasi perjalanan penduduk bentuk KPY belum memiliki bentuk yang kompak.
\end{abstract}

Keyword in Bahasa: Perkotaan, Perilaku Perjalanan, Transportasi, Critical Path Method

\begin{abstract}
Mobilization in urban areas has increased every year along with the population growth and urban's development. Travel behaviors of the population in urban areas can be classified based on their travel characteristics. The identification of communities' travel behavior of Yogyakarta is based on the origin - destination and length of trip based on age characteristics. It will effects the travel patterns in the urban environment through spatial mapping. The method used in this research is critical path method. Critical Path Method (CPM) is used to determine the optimum path taken by the community based on its duration, which in this study CPM is used to determine the average travel of the community based on age groups when viewed from distance, length of trip and the number of daily trips. Based on the analysis, it shows that the average age of 15-22 years and 3137 years have the highest travel time, which is about 9 hours and the average age of 23-30 years traveled the longest by $12.5 \mathrm{~km}$. The average mobilization of travel behaviors in KPY is to the urbancenter of Yogyakarta. The KPY urban form does not have a compact form.
\end{abstract}

Keywords: Urban, Travel Behavior, Transportation, Critical Path Method

\footnotetext{
${ }^{1}$ Perencanaan Wilayah dan Kota, Institut Teknologi Nasional Yogyakarta

${ }^{2}$ Perencanaan Wilayah dan Kota, Universitas Gadjah Mada
} 


\section{PENDAHULUAN}

Penelitian terkait faktor - faktor terkait karakteristik perjalanan telah banyak dikemukakan oleh para peneliti terdahulu. Faktor-faktor yang mempengaruhi karakteritik perilaku perjalanan dapat meliputi faktor ekonomi, sosial, dan lingkungan (Crane, 2000; Albayati, Sipe, Alizadeh, \& Tomerini, 2014). Hubungan antara transportasi, rumah dan bentuk perkotaan juga turut mempengaruhi karakteristik perjalanan. Keterjangkauan rumah tangga tidak hanya dipengaruhi oleh jenis perumahan, tetapi juga oleh pilihan moda transportasi serta perilaku perjalanan lebih banyak dipengaruhi oleh jenis area tempat masyarakat (perkotaan / pedesaan) dibandingkan dengan lokasi dalam sistem pemukiman (Dewita, dkk., 2019; Bartosiewicz dan Pielesiak, 2019).

Perencanaan kota yang efisien dapat dilihat berdasarkan perencanaan transportasi perkotaan yang terintegrasi dalam penyediaan transportasi umum bagi masyarakat baik dalam perkotaan dan pinggiran kawasan perkotaan, salah satunya melalui studi terkait perilaku perjalanan penduduknya (Ambarwati, et al., 2016). Studi tersebut merupakan salah satu upaya dalam pengendalian kawasan urban sprawl. Meluasnya wilayah perkotaan mengakibatkan berbagai permasalahan perkotaan seperti inefisiensi penggunaan lahan, pemborosan energi dan waktu akibat panjangnya jarak tempuh, kemacetan, dan permasalahan lain yang berdampak pada penurunan kualitas ruang perkotaan. Di sisi lain, berkembangnya kawasan perkotaan juga berdampak pada semakin tingginya mobilitas masyarakat untuk memenuhi kebutuhan pergerakan harian.

Kebijakan untuk mengurangi penggunaan kendaraan pribadi, khususnya sepeda motor dan mobil, serta mempromosikan penggunaan moda transportasi aktif seperti jalan kaki, sepeda, dan transportasi publik, telah banyak diimplementasikan negara-negara berkembang. Pengembangan bentuk ruang kota yang kompak dengan skala ruang kecil, merupakan respon terhadap fenomena urban sprawl dan mobilitas perkotaan dan dapat menjadi strategi yang efektif dalam mengurangi ketergantungan terhadap kendaraan bermotor. Karakteristik perjalanan dari segi sosial ekonomi dapat memiliki pengaruh dalam perilaku perjalanan, akan tetapi pola lingkungan juga memiliki pengaruh paling besar terhadap perilaku perjalanan (Nkeki, F.N dan Asikhia, M.O, 2019). Tarikan bangkitan yang dipengaruhi oleh pola penggunaan lahan ini yang mempengaruhi karakteristik perilaku perjalanan. Peningkatan urbanisasi di Yogyakarta menyebabkan semakin tingginya tingkat mobilitas masyarakat yang tinggal di dalamnya.

Dominasi perkembangan wilayah di Yogyakarta bergerak ke arah pusat wisata dan pendidikan, banyaknya pendatang juga memicu pola perkembangan di DIY. Kajian ini dilakukan untuk mengetahui pola perilaku perjalanan masyarakat di wilayah perkotaan Yogyakarta serta mengetahui rata-rata perjalanan masyarakat berdasarkan kelompok usia melalui metode Critical Path Method (CPM). Banyak peneliti menggunakan metode CPM dalam untuk mencari waktu yang paling efektif dalam penentuan pekerjaan konstruksi, manajemen, transportasi (Ahmed, F., 2018; Yang, J.B dan Kao, K.C., 2012; Zareei, S., 2018; Cheng, Y., 1996; Takakura, Y., et al., 2019). Para peneliti sebelumnya, menentukan waktu yang paling efektif untuk mengurangi biaya produksi yang ditimbulkan akibat lamanya sebuah pekerjaan. Pada bidang transportasi peneliti sebelumnya menggunakannya untuk membuat jadwal perjalanan transportasi umum seperti jadwal kereta api dan jadwal perjalanan masyarakat (Cheng, Y. 1996; Ahmed, F., 2018). Penjadwalan melalui CPM adalah penerapan hubungan logika dan prioritas antar kegiatan (Ahmed, F., 2018).

Dalam penelitian ini, metode CPM untuk menentukan pola perilaku perjalanan berdasarkan usia untuk melihat efektivitas waktu berdasarkan pola kegiatan yang dilakukan. Hal tersebut dapat berdampak pada pola ruang kawasan perkotaan untuk membentuk kota yang kompak dalam mempersingkat waktu perjalanan masyarakat dari tujuan satu ke tujuan lainnya. 


\section{METODE}

Data pada penelitian diperoleh dari hasil survey primer dan sekunder, data yang diperlukan pada penelitian ini mencakup perilaku perjalanan, karakteristik sosialekonomi, dan karakteristik lingkungan terbangun. Pengumpulan data melalui kuisioner, dilakukan guna mengumpulkan data terkait perilaku perjalanan berdasarkan tujuan perjalanan di Kawasan Perkotaan Yogyakarta (KPY). Sesuai dengan tujuan penelitian ini, obyek yang menjadi populasi penelitian adalah masyarakat yang tinggal di lokasi studi. Adapun pemilihan sample responden yang digunakan dalam penelitian adalah dengan menggunakan metode simple random sampling. Sampel diambil dari populasi penduduk di KPY berjumlah 1.053.711 jiwa. Metode slovin digunakan untuk penentuan sampel penelitian dapat menggunakan rumus Slovin dengan tingkat kepercayaan 95\%, sampling error 0,5 , sebesar 400 responden. Variabel yang dibutuhkan dalam analisis ini lebih jelasnya dapat dilihat pada Tabel 1 di bawah ini:

Tabel 1. Operasionalisasi Variabel Dan Kebutuhan Data Penelitian

\begin{tabular}{ll}
\hline \multicolumn{1}{c}{ Variabel } & \multicolumn{1}{c}{ Sumber Data } \\
\hline - jumlah perjalanan & - Survei primer: kuisioner \\
- frekuensi perjalanan & - Survei sekunder: Dinas Perhubungan \\
- vehicle miles travel (VMT) & DIY \\
- moda perjalanan & \\
Personal attributes: & \\
- Struktur rumah tangga & \\
- Pendapatan & \\
- Pekerjaan & \\
- Usia & \\
- Kepemilikan kendaraan & \\
\hline
\end{tabular}

Sumber: Peneliti, 2019

\section{METODE}

Penelitian ini menggunakan pendekatan kuantitatif melaui GIS dengan metode Critical Path Methode (CPM). Pengolahan data pada penelitian ini menggunakan metode CPM yang hasilnya akan diterjemahkan kedalam bentuk peta analisis, selanjutnya digunakan pendekatan kualitatif untuk menjelaskan karakteristik perjalanan masingmasing kelompok usia. Metode CPM digunakan untuk penetuan waktu optimum suatu pekerjaan dalam hal ini adalah perjalanan. Adapun rumus CPM lama perjalanan $1+$ lama aktivitas + lama perjalanan 2. Secara umum metode CPM memiliki skema sebagai berikut:

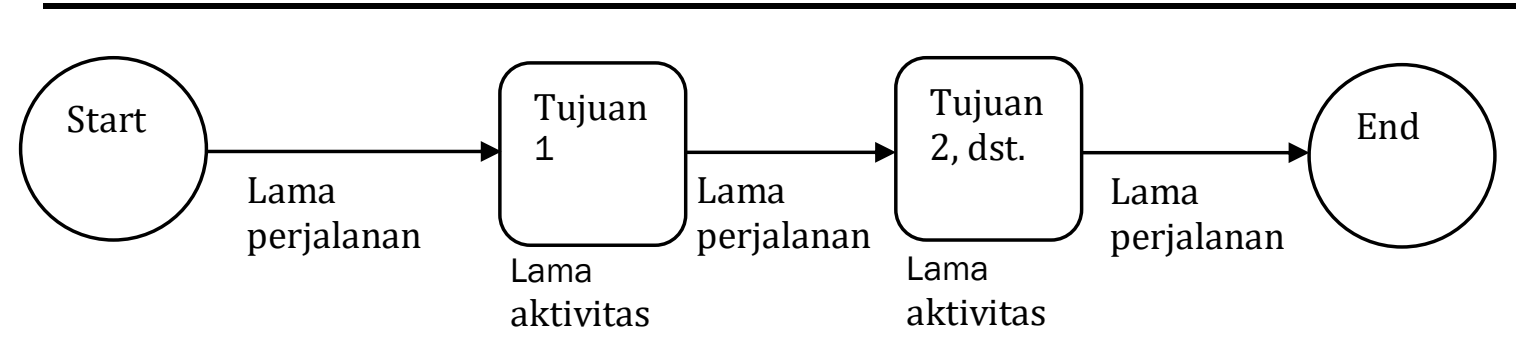

Sumber: Vanhoucke, 2012, dengan modifikasi

Figure 1. Metode CPM

Untuk lebih jelasnya dapat dilihat pada diagram tahapan penelitian berikut: 


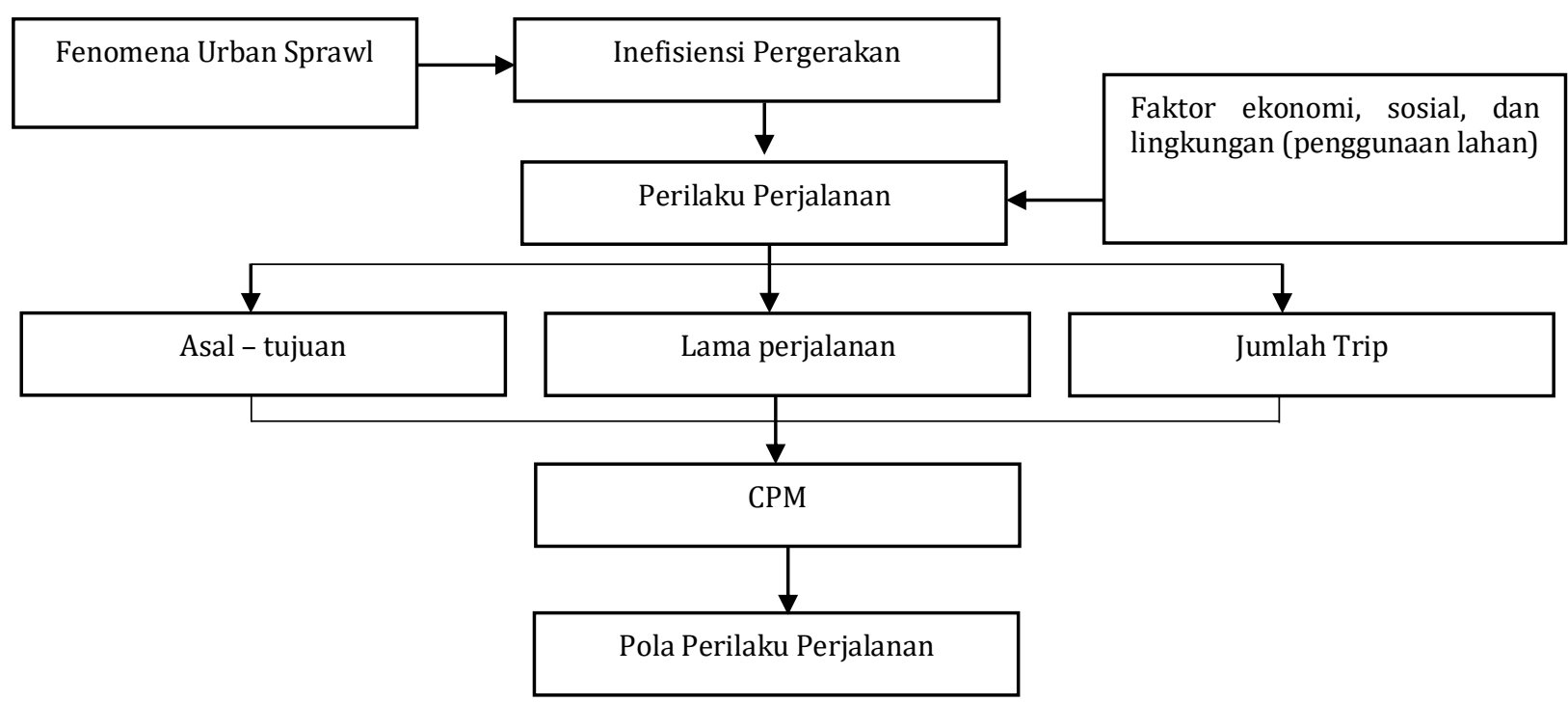

Sumber: Peneliti, 2019

Figure 2. Diagram Alir Penelitian

\section{HASIL DAN PEMBAHASAN}

Faktor sosial-ekonomi seperti umur, pendapatan dan status memiliki dampak yang signifikan terhadap pola perilaku perjalan. Perilaku perjalanan berkaitan dengan lokasi permukiman dalam pemilihan lokasi permukiman dan moda transportasi (Dewita, dkk., 2019; Bartosiewicz dan Pielesiak, 2019). Faktor ekonomi, sosial dan lingkungan terbangun menjadi hal mendasar dalam perilaku perjalanan. Karakteristik sosial yang dihubungkan dengan kelompok usia berkaitan dengan aktivitas perilaku responden dalam melakukan perjalanan. Pembagian karateristik usia didasarkan pada karakteristik rumah tangga. Karakteristik rumah tangga berkaitan dengan status pekerjaan atau aktivitas responden. Keterkaitan antara kebiasaan penduduk, ruang publik, dan infrastuktur transportasi yang didukung melalui kebijakan dan kondisi sosial lingkungan menciptakan perilaku perjalanan penduduk. Secara umum dapat ditunjukkan diagram pada gambar3.

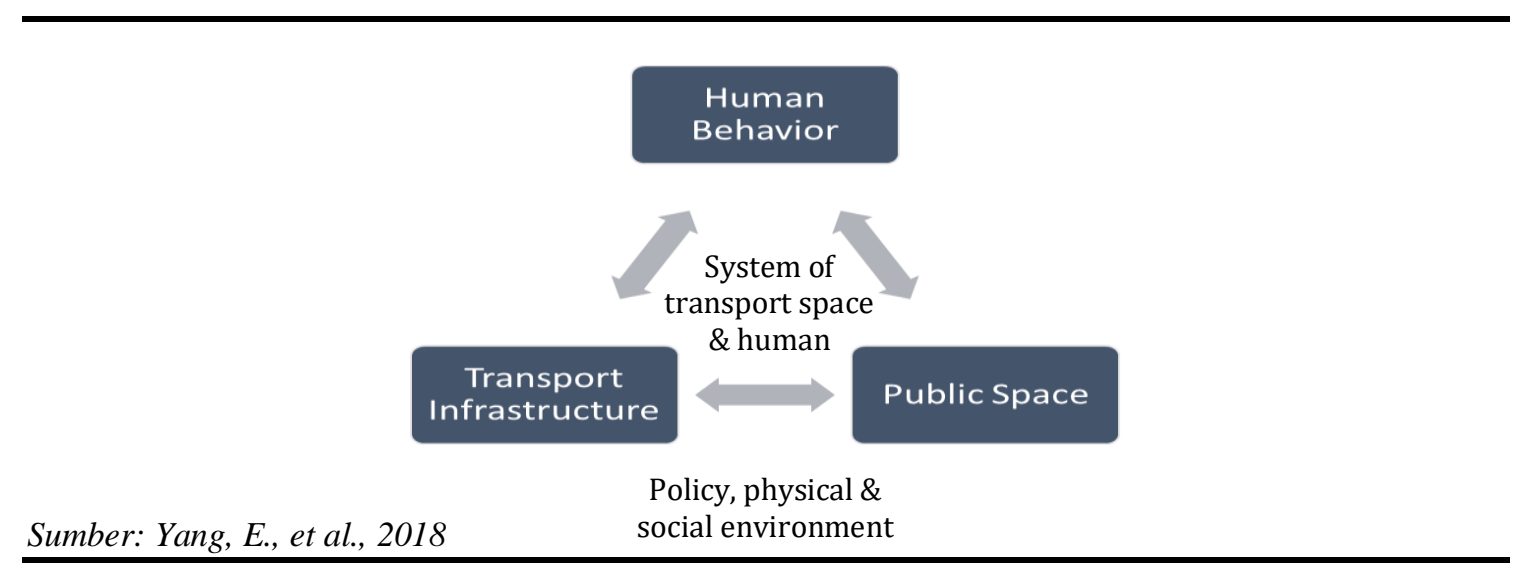

Figure 3. Hubungan Sistem Transportasi, Manusia Dan Ruang Dalam Menciptakan Perilaku Perjalanan 
Kelompok usia yang diidentifikasi perilaku perjalanannya meliputi usia 7-14 tahun, usia 15-22 tahun, usia 23-30 tahun, usia 31-37 tahun, usia 38-45 tahun, usia 46-53 tahun, usia 54-61 tahun, usia >61 tahun. Pengkategorian usia didasarkan dari aktivitas yang meliputi sekolah, rumah tangga, pekerja, dan non produktif. Rute perjalanan masingmasing kelompok usia rata-rata melakukan join trip yakni melakukan lebih dari sekali perjalanan. Aktifitas perilaku perjalanan ini meliputi dari asal - tujuan 1 - tujuan 2 - asal. Jumlah responden dalam melakukan perjalanan juga mempengaruhi banyaknya perjalanan yang dilakukan berdasarkan kelompok usia. Kelompok usia memiliki pengaruh terhadap lama perjalanan, panjang perjalanan, dan jumlah perjalanan. Identifikasi pola perjalanan masyarakat berdasarkan komponen usia adalah sebagai berikut:

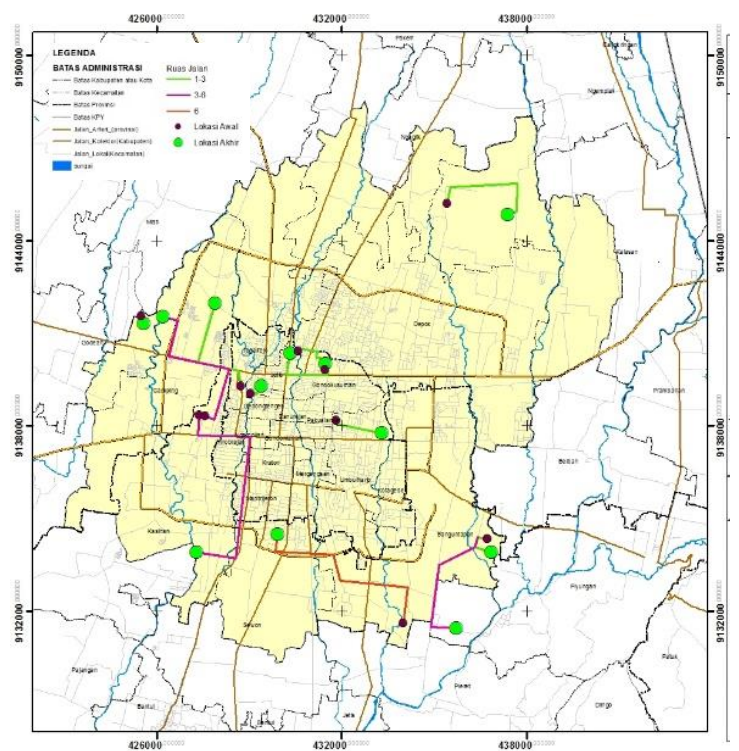

Pola Perjalanan Usia 7-14 Tahun

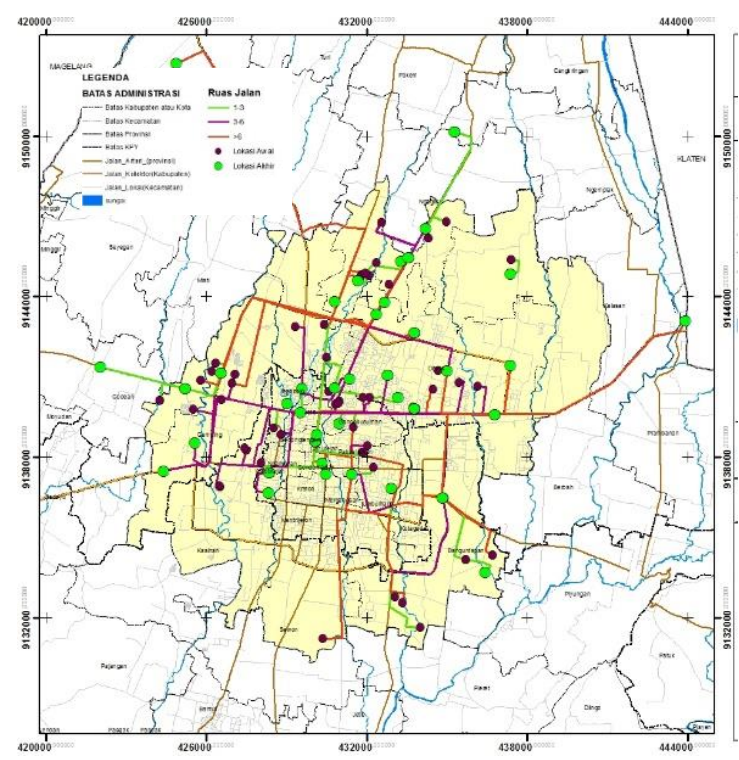

Pola Perjalanan Usia 23-30 Tahun

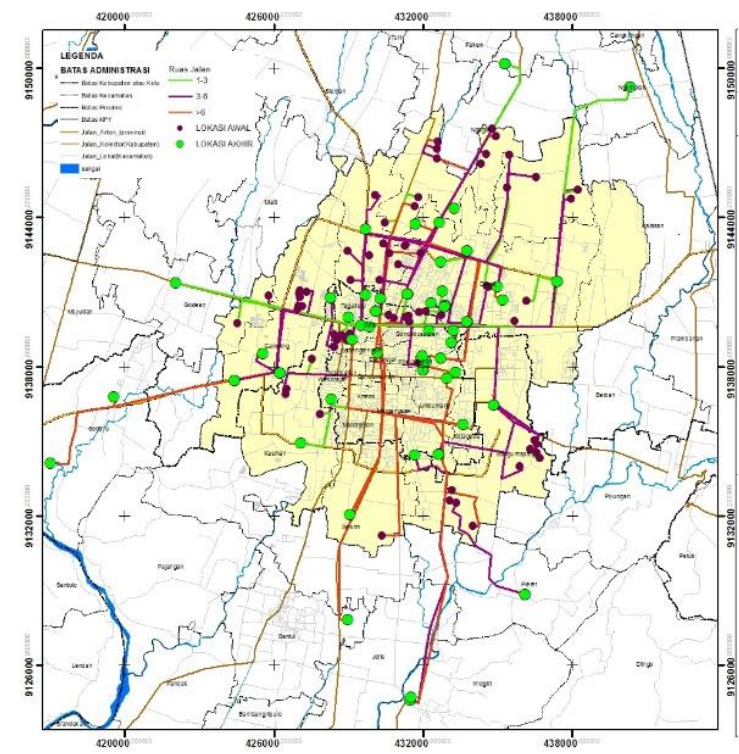

Pola Perjalanan Usia 15-22 Tahun

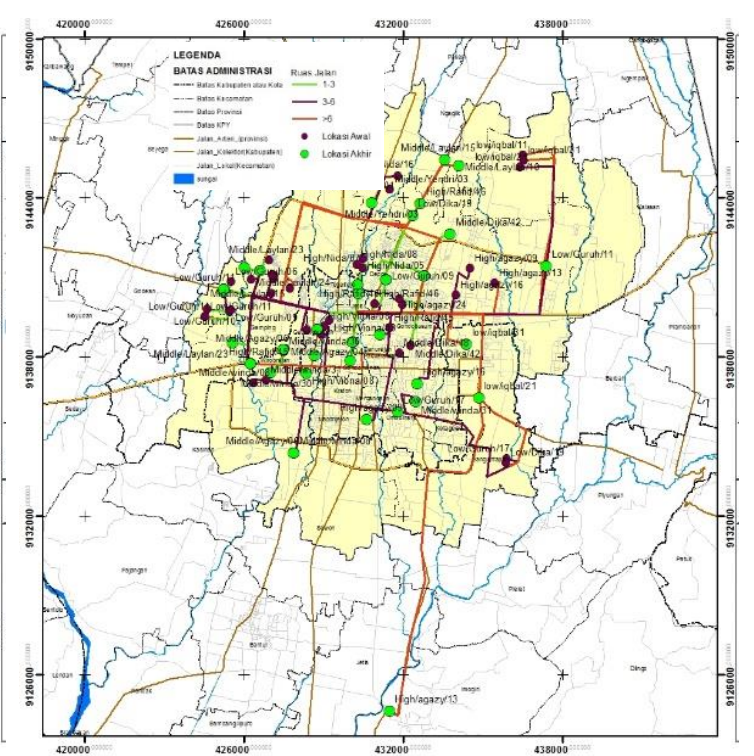

Pola Perjalanan Usia 31-37 Tahun 


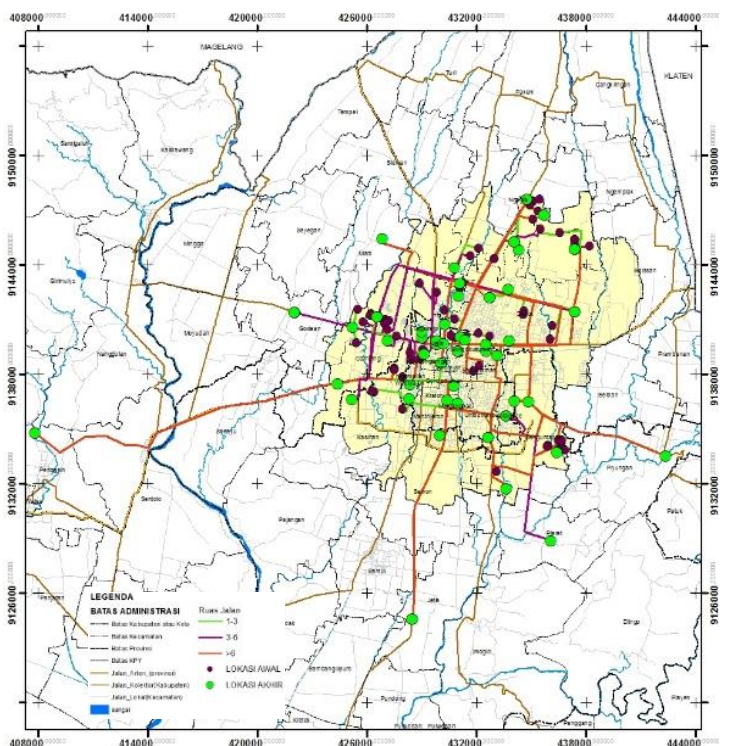

Pola Perjalanan Usia 38-45 Tahun

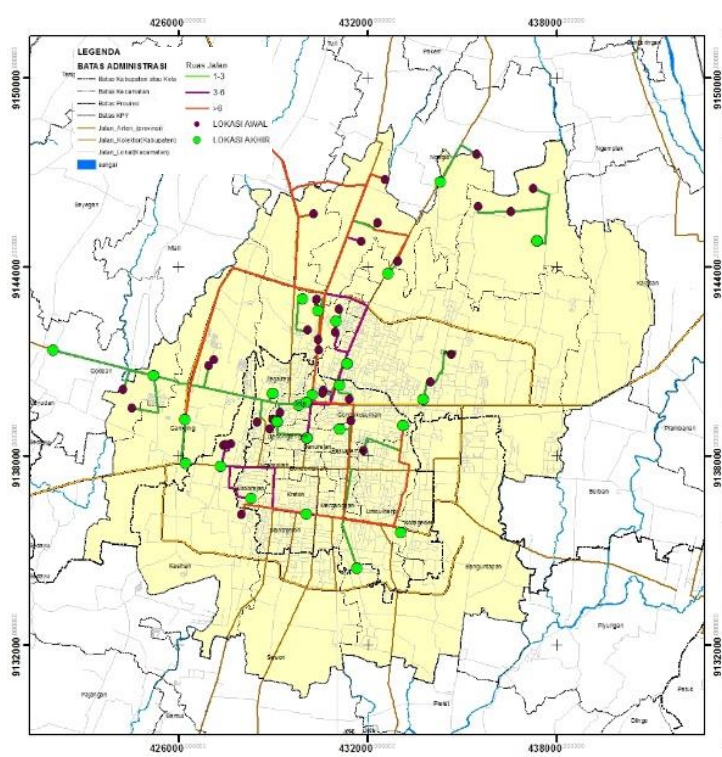

Pola Perjalanan Usia 54-61 Tahun

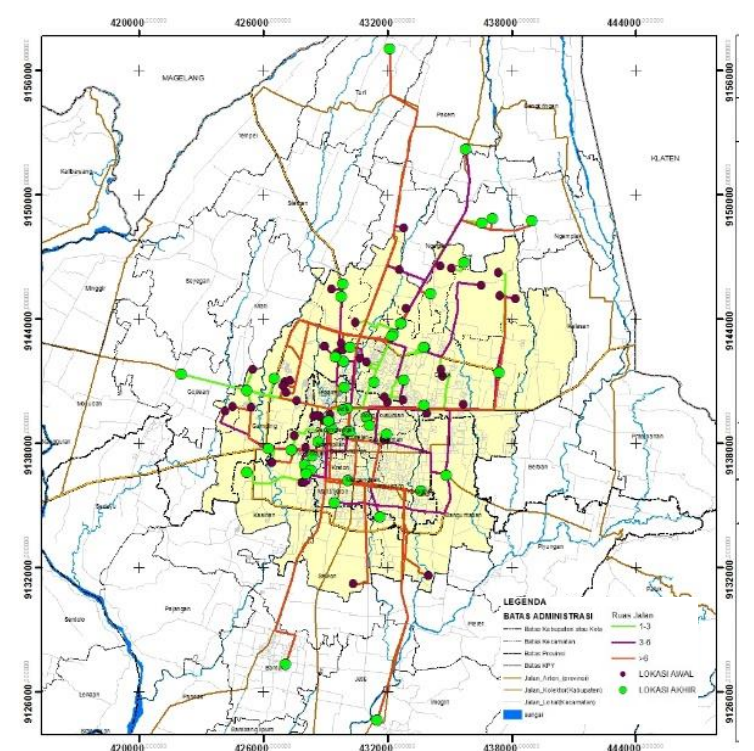

Pola Perjalanan Usia 46-53 Tahun

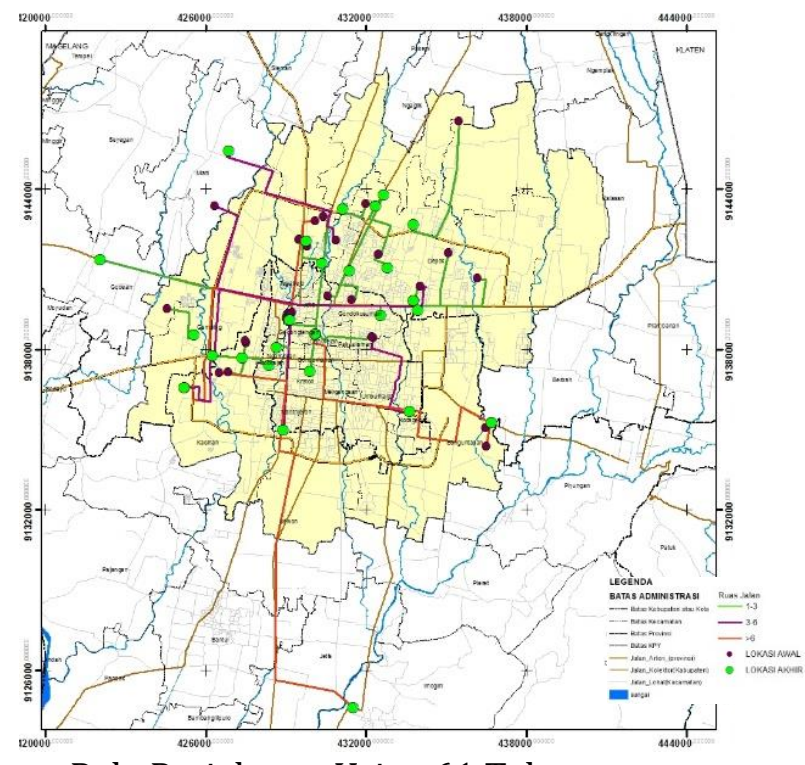

Pola Perjalanan Usia >61 Tahun

Sumber: hasil analisis, 2019

\section{Figure 4. Peta Pola Perjalanan Berdasarkan Kelompok Usia}

Berdasarkan hasil analisis di atas diketahui bahwa non produktif melakukan single trip dengan karakteristik perjalanan jarak pendek, semakin produktif komponen usia maka diketahui responden melakukan aktivitas perjalanan join trip yakni lebih dari satu kali dengan jarak perjalanan yang panjang. Dimana aktivitas komponen sebaran lokasi asal - tujuan melalui ruas-ruas jalan utama hingga memiliki tingkat kepadatan $>6 \mathrm{kali}$ ruas yang sama dilalui oleh responden. Aktivitas kegiatan kelompok usia didominasi dengan rute perjalanan dari sub-urban menuju kawasan urban. Hal tersebut dipengaruhi oleh lingkungan (pola penggunaan lahan) yang merupakan kawasan tarikan perjalanan. Kawasan bangkitan perjalanan didominasi pada kawasan sub urban dimana area lokasi permukiman berada. Aktivitas rute perjalanan masing-masing kelompok usia diidentifikasi melalui jarak, waktu, banyak perjalanan, dan lokasi. Rata-rata perjalanan 
didapat dari hasil perhitungan rata-rata durasi perjalanan dari tiap-tiap kelompok usia menggunakan metode CPM. Berikut tabel 2 hasil analisis rata-rata perjalanan berdasarkan kelompok umur:

Tabel 2. Tabel Rata-Rata Perjalanan Berdasarkan Kelompok Umur

\begin{tabular}{lcccl}
\hline \multicolumn{1}{c}{ Kelompok Usia } & Jarak & Waktu & Trip & \multicolumn{1}{c}{ Path } \\
\hline Usia 7-14 Tahun & $4,7 \mathrm{Km}$ & 8 Jam & 1 Kali & rumah-sekolah-rumah \\
Usia 15-22 Tahun & $6,8 \mathrm{Km}$ & 9 Jam & 2 Kali & rumah-sekolah-lainnya-rumah \\
Usia 23-30 Tahun & $12,5 \mathrm{Km}$ & 8 Jam & 2 Kali & rumah-mengantar-rumah- \\
& & & & menjemput-rumah \\
Usia 31-37 Tahun & $6 \mathrm{Km}$ & 9 Jam & 2 Kali & rumah-tempat kerja-lainnya-rumah \\
Usia 38-45 Tahun & $6 \mathrm{Km}$ & 7 Jam & 1 Kali & rumah-tempat kerja-rumah \\
Usia 46-53 Tahun & $4 \mathrm{Km}$ & 7 Jam & 1 Kali & rumah-tempat kerja-rumah \\
Usia 54-61 Tahun & $3,6 \mathrm{Km}$ & $5 \mathrm{Jam}$ & 1 Kali & rumah-lainnya-rumah \\
Usia >61 Tahun & $5,5 \mathrm{Km}$ & 5 Jam & 1 Kali & rumah-lainnya-rumah \\
\hline
\end{tabular}

Sumber: hasil analisis, 2019

Berdasarkan tabel di atas diketahui bahwa jarak perjalanan paling tinggi dilakukan oleh kelompok usia 23-30 tahun dan terpendek dilakukan usia 54-61 tahun. Rute optimum komponen usia dilakuakan antara 5 - 9 jam. Pada kelompok usia 15-22 tahun dan 31-37 tahun memiliki rute optimum sebesar 9 jam perjalanan dengan rute minimum $2 x$ trip. Kelompok usia tidak produktif $54-61$ tahun dan $>61$ tahun memiliki rute optimum sebesar 5 jam perjalanan dengan rute 2kali trip dan jarak terpendek 3-5 km. Pengaturan lokasi tarikan dan bangkitan dapat mengungkapkan keterjangkauan. Efek dari keterjangkauan baik lama perjalanan, rute perjalanan, jarak, dan jumlah trip ini adalah biaya transportasi (Dewita, dkk., 2019). Efektivitas rute optimum masing-masing kelompok usia melalui pengaturan penggunaan lahan dapat menurunkan jarak dan waktu perjalanan sehingga dapat menghemat biaya transportasi.

Letak lokasi permukiman sebagai bagian dari bangkitan perjalanan mempengaruhi dalam penentuan jarak dan aktivitas perjalanan. Rata-rata perjalanan dari kawasan sub urban ke kawasan urban memiliki jarak $14 \mathrm{~km}$ menuju tempat kerja dan membutuhkan waktu berkisar 25,5 menit (Bartosiewicz dan Pielesiak, 2019). Pada rute perjalanan optimum di kawasan studi membutuhkan waktu dari rumah menuju tujuan pertama yakni memerlukan waktu 20 menit dengan jarak tempuh 12,5 km. Sedangkan rute optimum pada kawasan perkotaan menuju kawasan perkotaan memiliki rerata 11,7 km dengan waktu tempuh 26,4 menit dimana aktivitas dalam perkotaan lebih memiliki waktu tempuh yang lebih lama dengan jarak yang lebih dekat (Bartosiewicz dan Pielesiak, 2019). Pada kawasan penelitian memiliki jarak tempuh 4,7 km dengan waktu tempuh juga lebih singkat yakni 15 menit. Aktivitas kegiatan melalui perilaku perjalanan juga dipengaruhi oleh kegiatan komuter yang dilakukan dengan rute sekali perjalanan / tujuan.

Tabel 3. Critical Path Responden

\begin{tabular}{lrrrrrrrr}
\hline $\begin{array}{l}\text { Kelompok } \\
\text { Usia }\end{array}$ & Start & $\begin{array}{c}\text { Lama } \\
\text { perjalanan } \\
\text { (2menit) }\end{array}$ & $\begin{array}{c}\text { Tujuan } \\
1 \text { (jam) }\end{array}$ & $\begin{array}{c}\text { Lama } \\
\text { perjalanan } \\
2 \text { (menit) }\end{array}$ & $\begin{array}{c}\text { Tujuan } \\
2 \text { (jam) }\end{array}$ & $\begin{array}{c}\text { Lama } \\
\text { perjalanan } \\
3 \text { (menit) }\end{array}$ & End & Total \\
\hline $\begin{array}{l}\text { Usia 7-14 } \\
\text { Tahun }\end{array}$ & 0 & 10 & 8 & - & - & 10 & 0 & 8 jam \\
$\begin{array}{l}\text { Usia 15-22 } \\
\text { Tahun }\end{array}$ & 0 & 10 & 6 & 10 & 3 & 10 & 0 & 9 jam \\
$\begin{array}{l}\text { Usia 23-30 } \\
\text { Tahun }\end{array}$ & 0 & 30 & 6 & 10 & 1 & 30 & 0 & 8 jam \\
$\begin{array}{l}\text { Usia 31-37 } \\
\text { Tahun }\end{array}$ & 0 & 20 & 6 & 10 & 3 & 20 & 0 & 9 jam \\
$\begin{array}{l}\text { Usia 38-45 } \\
\text { Tahun }\end{array}$ & 0 & 10 & 7 & - & - & 10 & 0 & 7 jam \\
\hline
\end{tabular}




\begin{tabular}{|c|c|c|c|c|c|c|c|c|}
\hline $\begin{array}{l}\text { Kelompok } \\
\text { Usia }\end{array}$ & Start & $\begin{array}{c}\text { Lama } \\
\text { perjalanan } \\
1 \text { (menit) }\end{array}$ & $\begin{array}{l}\text { Tujuan } \\
1 \text { (jam) }\end{array}$ & $\begin{array}{c}\text { Lama } \\
\text { perjalanan } \\
2 \text { (menit) }\end{array}$ & $\begin{array}{l}\text { Tujuan } \\
2 \text { (jam) }\end{array}$ & $\begin{array}{c}\text { Lama } \\
\text { perjalanan } \\
3 \text { (menit) }\end{array}$ & End & Total \\
\hline $\begin{array}{l}\text { Usia 46-53 } \\
\text { Tahun }\end{array}$ & 0 & 30 & 6 & - & - & 30 & 0 & 7 jam \\
\hline $\begin{array}{l}\text { Usia 54-61 } \\
\text { Tahun }\end{array}$ & 0 & 15 & 5 & - & - & 15 & 0 & 5 jam \\
\hline $\begin{array}{l}\text { Usia }>61 \\
\text { Tahun }\end{array}$ & 0 & 20 & 5 & - & - & 20 & 0 & 5 jam \\
\hline
\end{tabular}

Sumber: hasil analisis, 2019

Perkembangan kelompok usia dalam pemilihan tujuan aktivitas yang berbeda, mempengaruhi perilaku perjalanan di KPY. Perilaku perjalanan di KPY masih dalam tahapan yang rata-rata dialami oleh kawasan perkotaan sedang. Dimana rute optimum kawasan masih didominasi oleh perjalanan single trip dengan lama perjalanan masih dalam tahap kewajaran dibandingkan dengan lama perjalanan pada kota besar. Tren perilaku perjalanan saat ini diamati, dinamis peningkatan kualitas dan aksesibilitas infrastruktur jalan, seperti serta kurangnya pengembangan transportasi umum yang proporsional.

Kelebihan dari metode CPM ini dapat melihat rincian kegiatan dan hubungan antar kegiatan (Ahmed, F., 2018). Dalam penelitian ini diidentifikasi hubungan antar kegiatan yang dilakukan responden dalam melakukan perjalanan berdasarkan usia, sedangkan peneliti sebelumnya melihat hubungan antar kegiatan untuk penjadwalan kegiatan dalam proyek konstruksi yang dianggap penting sehingga tercapainya efektifitas waktu antar kegiatan (Ahmed, F., 2018). Pembentukan kota yang kompak menjadi salah satu alternative dalam penentuan rute perjalanan untuk efektifitas waktu.

Peneliti sebelumnya menggunakan metode regresi untuk menentukan pola perilaku perjalanan melalui identifikasi perpindahan lokasi permukiman/ relokasi (Guo, Y. dan Peeta, S., 2020). Hasil peneliti sebelumnya menjelaskan bahwa terdapat beberapa perubahan trip dari yang 6 trip untuk pada lokasi sebelum direlokasi menjadi lebih dan tergantung pada aksesibilitas yang dapat dicapai. Berdasarkan hal tersebut, pada metode CPM diketahui bahwa rata-rata trip yang dilakukan responden pada satu hari ini yakni 3 trip yang diakibatkan durasi perjalanan dari responden cukup lama. Melalui metode CPM dapat diidentifikasi bahwa jarak rata-rata pola perjalanan responden yakni berkisar 4-12 $\mathrm{km}$ dengan durasi perjalanan 10 - 30 menit antar kegiatan menjadikan trip yang dihasilkan sedikit karena adanya waktu jeda/ delay akibat kemacetan dan harus ditempuh menggunakan kendaraan. Pengektifitasan durasi dalam sebuah pekerjaan menjadi penting untuk menghemat biaya dan komponen aktivitas yang didahulukan (Kiran, 2019). Pada penelitian ini, pengektifitasan durasi perjalanan menjadi penting dalam meningkatkan aktivitas antar kegiatan dalam pola perilaku perjalanan.

\section{KESIMPULAN}

Berdasarkan hasil pembahasan di atas maka dapat disimpulkan terkait pola perilaku perjalanan masyarakat di wilayah perkotaan Yogyakarta melalui rata-rata perjalanan masyarakat berdasarkan kelompok usia melalui metode CPM. Usia produktif meliputi rentang usia 15 - 53 tahun dimana masyarakat masih aktif melakukan perjalanan dengan pola yang bervariasi dengan rentang waktu perjalanan yakni 8 jam, panjang perjalanan 4 $12,5 \mathrm{~km}$. Pola perjalanan pada usia produktif memiliki pola rerata dua kali trip yakni rumah - kantor - lainnya - rumah. Pada usia non produktif yakni usia 7 - 14 tahun dan $>54$ tahun memiliki rerata lama waktu perjalanan antara 6,5 jam dengan panjang perjalanan 3 - $5 \mathrm{~km}$ dengan pola perjalanan sekali trip yakni rumah - sekolah/lainnya - 
rumah. Dimana sistem tarikan berupa kawasan pendidikan, perkantoran, dan kegatan lainnya menjadi salah satu faktor dari tujuan perjalanan.

Rute perjalanan didominasi kegiatan antara kawasan sub urban menuju daerah urban dan aktivitas dalam kawasan urban dimana jarak tempuh dan waktu tempuh antar kawasan memiliki perbandingan yang positif. Belum mengindikasikan adanya bentuk kota besar dan masih memiliki bentuk yang menyebar dan belum kompak. Hal tersebut dapat diidentifikasi terkait asal, tujuan dan lama perjalanan yang masih didominasi jarak lebih dari $3 \mathrm{~km}$ dimana jarak ini tidak dapat ditempuh melalui aktivitas berjalan kaki. Kepadatan rute jalan yang dilalui diketahui dari banyaknya trip yang melalui jalan yang sama sehingga dapat meningkatkan kepadatan lalu lintas. Penyediaan transportasi massal pada rute-rute jalan yang dilalui oleh $>6$ kali trip perjalanan dapat menjadi pengendali dari dampak urban sprawl selain melalui penataan ruang terkait penataan kawasan tarikan dan bangkitan agar dapat lebih kompak.

Kebijakan kota kompak memungkinkan jarak pendek dan kepadatan cukup tinggi, dan karenanya durasi perjalanan singkat, perjalanan aktif, dan lebih sedikit ketergantungan pada mobil, dapat meningkatkan kepuasan perjalanan. Perhatian harus diberikan kepada kebijakan perumahan sehingga manfaat daerah perkotaan pusat yang kompak (Mouratidis, K., Ettema, D., Næss, P. 2019). Pola lokasi, konfigurasi geografis wilayah perkotaan, merupakan faktor dalam rumah tangga strategi adaptif yang sebagian menentukan kemungkinan untuk mengurangi perjalanan (Nielsen, T.A.S. 2015). Hal tersebut perlu diadaptasi dalam perkembangan KPY agar tercipta perjalanan yang lebih kompak dan mengurangi efek dari urban sprawl.

\section{PERNYATAAN RESMI}

Artikel ini merupakan luaran dari penelitian yang dibiayai oleh Hibah Penelitian Skema Kerjasama Antar Perguruan Tinggi dari Direktorat Riset dan Pengabdian Masyarakat Kemenristekdikti dengan Nomor Kontrak No.111/SP2H/PL/DRPM/2019.

\section{DAFTAR PUSTAKA}

Ahmed, F. (2018). Impact Of Critical Path Method (CPM) Of Scheduling On On-Time Completion Of Transportation Projects. Theses : University of South Carolina

Ambarwati, L., Verhaeghe, R., van Arem, B., \& Pel, A. J. (2017). Assessment of transport performance index for urban transport development strategies-Incorporating residents' preferences. Environmental Impact Assessment Review, 63, 107-115. http://dx.doi.org/10.1016/i.eiar.2016.10.004

Albayati, D. M. F., Sipe, N. G., Alizadeh, T., \& Tomerini, D. (2015). The impact of urban form on travel behaviour in three Baghdad neighbourhoods affected by terrorism. Urban, Planning and Transport Research, 3(1), $32-45$.

Cheng, Y. (1996). Optimal train traffic rescheduling simulation by a knowledge-based system combined with critical path method. Simulation Practice and Theory, 4(6), 399-413.

Crane, R. 1999. The Impacts of Urban Form on Travel: A Critical Review. Working Paper, WP99RC1. Cambridge, MA: Lincoln Institute for Land Policy.

Bartosiewicz, B., \& Pielesiak, I. (2019). Spatial patterns of travel behaviour in Poland. Travel Behaviour and Society, 15, 113-122. https://doi.org/10.1016/j.tbs.2019.01.004

Dewita, Y., Burke, M., \& Yen, B. T. (2019). The relationship between transport, housing and urban form: Affordability of transport and housing in Indonesia. Case Studies on Transport Policy, https://doi.org/10.1016/j.cstp.2019.01.004

Kiran, D.R., 2019. Chapter 32 - Critical Path Method. A comperhensive approach. 457 - 471. https://doi.org/10.1016/B978-0-12-818364-9.00032-9

Guo, Y., \& Peeta, S. (2020). Impacts of personalized accessibility information on residential location choice and travel behavior. Travel Behaviour and Society, 19, 99-111.

Mouratidis, K., Ettema, D., \& Næss, P. (2019). Urban form, travel behavior, and travel satisfaction. Transportation research part A: policy and practice, 129, 306-320. https://doi.org/10.1016/i.tra.2019.09.002 
Nielsen, T. A. S. (2015). Changes in transport behavior during the financial crisis. An analysis of urban form, location and transport behavior in the greater Copenhagen area 2006-2011. Research in Transportation Economics, 51, 10-19. http://dx.doi.org/10.1016/i.retrec.2015.07.003

Nkeki, F. N., \& Asikhia, M. O. (2019). Geographically weighted logistic regression approach to explore the spatial variability in travel behaviour and built environment interactions: Accounting simultaneously for demographic and socioeconomic characteristics. Applied geography, 108 (27), 47-63. https://doi.org/10.1016/j.apgeog.2019.05.008

Yang, J. B., \& Kao, C. K. (2012). Critical path effect based delay analysis method for construction projects. International Journal of Project Management, 30(3), 385-397.

Yang, L., van Dam, K. H., Majumdar, A., Anvari, B., Ochieng, W. Y., \& Zhang, L. (2019). Integrated design of transport infrastructure and public spaces considering human behavior: A review of state-of-the-art methods and tools. Frontiers of Architectural Research, 8 (4), 429-453. https://doi.org/10.1016/j.foar.2019.08.003

Takakura, Y., Yajima, T., Kawajiri, Y., \& Hashizume, S. (2019). Application of critical path method to stochastic processes with historical operation data. Chemical Engineering Research and Design, 149, 195-208.

Vanhoucke, M. (2012). Project management with dynamic scheduling. Springer Berlin Heidelberg. DOI 10.1007/978-3-642-25175-7 3.

Zareei, S. (2018). Project scheduling for constructing biogas plant using critical path method. Renewable and Sustainable Energy Reviews, 81, 756-759. 